\title{
Do-not-resuscitate and treatment limitation decisions - Six years of experience from a Portuguese General Intensive Care Unit
}

(iD) Nuno Ferreira Monteiro'

(iD) sabel Simões ${ }^{2}$

(iD) Isabel Gaspar ${ }^{2}$

(iD) Eduarda Carmo²

1. Service of Internal Medicine, Hospital de Egas Moniz, Centro Hospitalar de Lisboa, Lisboa, Portugal 2. General Intensive Care Unit, Hospital de Egas Moniz, Centro Hospitalar de Lisboa Ocidental, Lisboa, Portugal

http://dx.doi.org/10.1590/1806-9282.65.9.1168

\section{SUMMARY}

OBJECTIVE: Treatment limitation, as well as do-not-resuscitate (DNR) directives, are difficult but important to improve patients' quality of life and minimize dysthanasia. We aimed to study the approach to withholding, withdrawal, and DNR decisions, patients' characteristics, and process documentation in a general Intensive Care Unit (ICU) in Portugal.

METHODS: A retrospective analysis of data regarding the limitation of treatment decisions collected from previously-designed forms and complemented by medical record consultation.

RESULTS: A total of 1602 patients were admitted to the ICU between 2011 and 2016. DNR decisions were documented in 127 cases (7.9\%). Patients with treatment limitations were older and had higher Simplified Acute Physiology Score II. The most frequent diagnosis preceding these decisions was sepsis $(52.0 \%, n=66)$; the most common main reason for limiting treatment was a poor prognosis of acute illness. Of the patients to whom a DNR was implemented, 117 (92.1\%) died in the ICU (40.1\% of the total number of ICU deaths), and hospital mortality was 100\%. Participants in these decisions, as well as types of treatment withdrawn and their respective timings, were not registered in medical records.

CONCLUSION: Treatment limitation and DNR decisions were relatively common, in line with other Southern European studies, but behind Northern European and North American centers. Patients with these limitations were older and more severely ill than patients without such decisions. Documentation of these processes should be clear and detailed, either in specific forms or computerized clinical records; there is room for improvement in this area.

KEYWORDS: Palliative care. Critical Care. Resuscitation Orders. Critical Illness. Withholding Treatment.

\section{INTRODUCTION}

Beginning in the 1950s, the development of artificial life-sustaining and/or organ-substituting techniques has progressively changed the definition of "death" into a relatively predictable and partially controlled process. This kind of advanced medical care is most often provided in intensive care units (ICU)'
Nowadays, between 20 and $30 \%$ of the global population die in ICU ${ }^{2,3}$; approximately one-fifth of all deaths in the United States occurs in or soon after a stay in the ICU, and half of the patients who die in a hospital has been admitted to an ICU during the 3 days prior to death ${ }^{4,5}$. 
Cardiopulmonary resuscitation (CPR) was approved for clinical use in 1974 by the American Heart Association; however, not initiating or suspending this intervention was also considered ethically appropriate when the perceived benefit was supplanted by the potential harm ${ }^{4}$. Since then, society has begun to reach a consensus that medical treatments, in general, may be withheld or withdrawn in certain situations ${ }^{6,7}$, even in an ICU setting. Indeed, the primary goal of intensive care is not to avoid death "at any cost", but rather returning critically ill patients to a quality of life they would find acceptable ${ }^{\mathbf{1 , 6}}$.

In order to avoid unnecessary treatments, a number of directives have been developed over time to establish adequate goals of care for terminal patients. The strict definition of "do-not-resuscitate" (DNR) means only "in the event of cardiac arrest, do not provide CPR", rather than an immediate cessation of all treatments. "Withholding therapy" is defined as a decision not to start or increase a life-sustaining intervention. In turn, "withdrawing therapy" is defined as a decision to actively stop a life-sustaining intervention that is presently being administered $^{8}$. When appropriate, a more in-depth three-level hierarchy for classifying decisions of limitation can also be used ("stop", “do not increase", and "do not start"), and more than one can be applied to the same patient simultaneously or sequentially ${ }^{1}$. Although, from an ethical standpoint, these decisions to withhold or withdraw treatment are labeled as equivalents, many clinicians still distinguish between the two, with the former being perceived as more "passive"1. More recently, to avoid the negative connotation sometimes attributed to these terms, a shift towards adopting "decisions to limit treatment" as a new, more encompassing terminology has been suggested ${ }^{2}$.

Even though ICU clinicians are frequently confronted with this kind of decisions, there is little documented evidence about how to approach these situations in practice. As an example, clinicians will sometimes decide to withdraw one life-sustaining therapy while continuing others; this method of incremental treatment withdrawal, also known as “stuttering withdrawal”, has been considered by some authors as a marker of suboptimal quality of care ${ }^{5}$.

The goal of this study was to evaluate the approach to DNR status and treatment limitation - both withholding and withdrawal (WhWd) - in a general ICU in
Portugal, in regard to the incidence of these decisions, patients' demographic and clinical characteristics, and how these processes were documented.

\section{METHODS}

In this study, we included all consecutive patients entering the mixed/general ICU at Hospital de Egas Moniz in Lisbon, Portugal, from 1 January 2011 to 31 December 2016.

During the ICU stay, patients were scored according to the Simplified Acute Physiology Score II (SAPS II) and grouped into disease categories based on the Acute Physiology, Age, and Chronic Health Evaluation (APACHE) III prognostic system: cardiovascular, respiratory, gastrointestinal, neurological, sepsis, trauma, metabolic, and other. Additionally, information on age, gender, type of admission, length of ICU stay, and outcome were recorded in a local database.

We retrospectively reviewed the computerized medical records of all patients who died during the ICU stay, as well as that of all patients who had DNR decisions implemented or treatment withheld or withdrawn. These patients were identified by consultation of a specific form, already employed in our ICU prior to the beginning of this study, where it is possible to record each DNR, withholding and withdrawal decision independently, as well as their respective dates, but which was not designed for this single purpose the HELICS-ICU protocol9. Reasons for withholding or withdrawing treatment and the type of treatment withheld or withdrawn were, when obtainable from medical records, registered using a form developed for this purpose. When such information was unavailable, it was classified as "not documented in clinical records".

A descriptive analysis of the data was performed with categorical variables presented as proportions/ percentages and continuous variables as median, mean, and standard deviation where applicable. Data analysis was conducted using Statistical Package for Social Sciences - SPSS ${ }^{\circledR}$ version 20.0 for Windows ${ }^{\circledR}$.

\section{RESULTS}

Over a period of six years, from a total of 1603 admissions, treatment limitation decisions were formally documented in 127 cases, corresponding to $7.9 \%$ of all ICU patients in this time frame. Eighty patients were male (63.0\%). The median age of DNR/WhWd patients was 71 
years $(50 ; 82)$, while the median of all patients admitted to the ICU was 65 years $(45 ; 80)$. The median SAPS II score for DNR/WhWd patients was $59(30 ; 79)$, whereas the overall median SAPS II during the same period was $39(22 ; 52)$. During the study period, the global median ICU stay was 10 days $(4 ; 14)$ whereas the median length of stay for DNR/WhWd patients was 12 days $(5 ; 20)$. Of the patients in whom DNR/WhWd was implemented, 117 (92.1\%) died in the ICU, corresponding to $40.1 \%$ of the total number of ICU deaths during this period $(\mathrm{n}=$ 316), while the in-hospital mortality for these patients was $100 \%$. [Figure 1]

The most frequent diagnoses which preceded DNR/ WhWd decisions were sepsis $(52.0 \%, \mathrm{n}=66)$, neurological event $(16.5 \%, \mathrm{n}=21)$, and respiratory failure $(10.2 \%$, $\mathrm{n}=13$ ). [Table 1] Upon ICU admission, $78.0 \%$ of patients were considered medical patients $(n=99)$ and $22.0 \%$ were considered surgical patients $(n=28)$ of which 6 were initially scheduled elective procedures (27.3\%) and 22 were unscheduled urgent interventions (72.8\%).

DNR status was formally documented in the HELICS-ICU form in $90.6 \%(n=115)$ of patients with either decision to withhold or withdraw treatment during their stay in the ICU. There was no difference in limitations between males and females. The decision to withhold treatment was formally documented in $63.0 \%(\mathrm{n}=80)$, while treatment withdrawal was established in $32.3 \%(n=41)$; in the remaining cases $(\mathrm{n}=6,7.7 \%)$ DNR orders were formally admitted, but neither decisions to withhold or withdraw treatments were put in place. In $41.5 \%(n=17)$ of cases where treatment withdrawal was documented, this decision was made at a later moment from documentation of DNR status. The justification of DNR/WhWd directives was not featured on the HELICS-ICU template for formal documentation of these decisions, and was instead obtained from clinical records when available; of those where predictors could be ascertained from the medical notes $(68.5 \%, \mathrm{n}=87)$, the most frequently identified causes of DNR/WhWd decisions were poor prognosis of acute illness due to non-responsiveness to medical therapy in $93.1 \%$ of cases $(\mathrm{n}=81)$ and limited subsequent relational quality of life in $49.4 \%(n=43)$ [Table 2]. Factors such as patient's age, patient's request, religious beliefs, or family's request were never documented to have been the cause for treatment limitation decision. Although the general incidence of withdrawal decisions was lower than withholding for all kinds of admissions, there was no statistically significant difference between the type of treatment limitation and whether patients were transferred as medical, unscheduled surgical or scheduled surgical admissions [Table 3].

Prognostic and therapeutic limitation discussion with family members was not routinely registered in clinical records, and as such, the frequency of these family conferences could not be accurately estimated. Similarly, the healthcare-providing participants in the decision process were not routinely documented in medical records.

FIGURE 1. FLOW CHART OF PATIENTS ADMITTED TO THE INTENSIVE CARE UNIT (ICU) AND THEIR OUTCOME

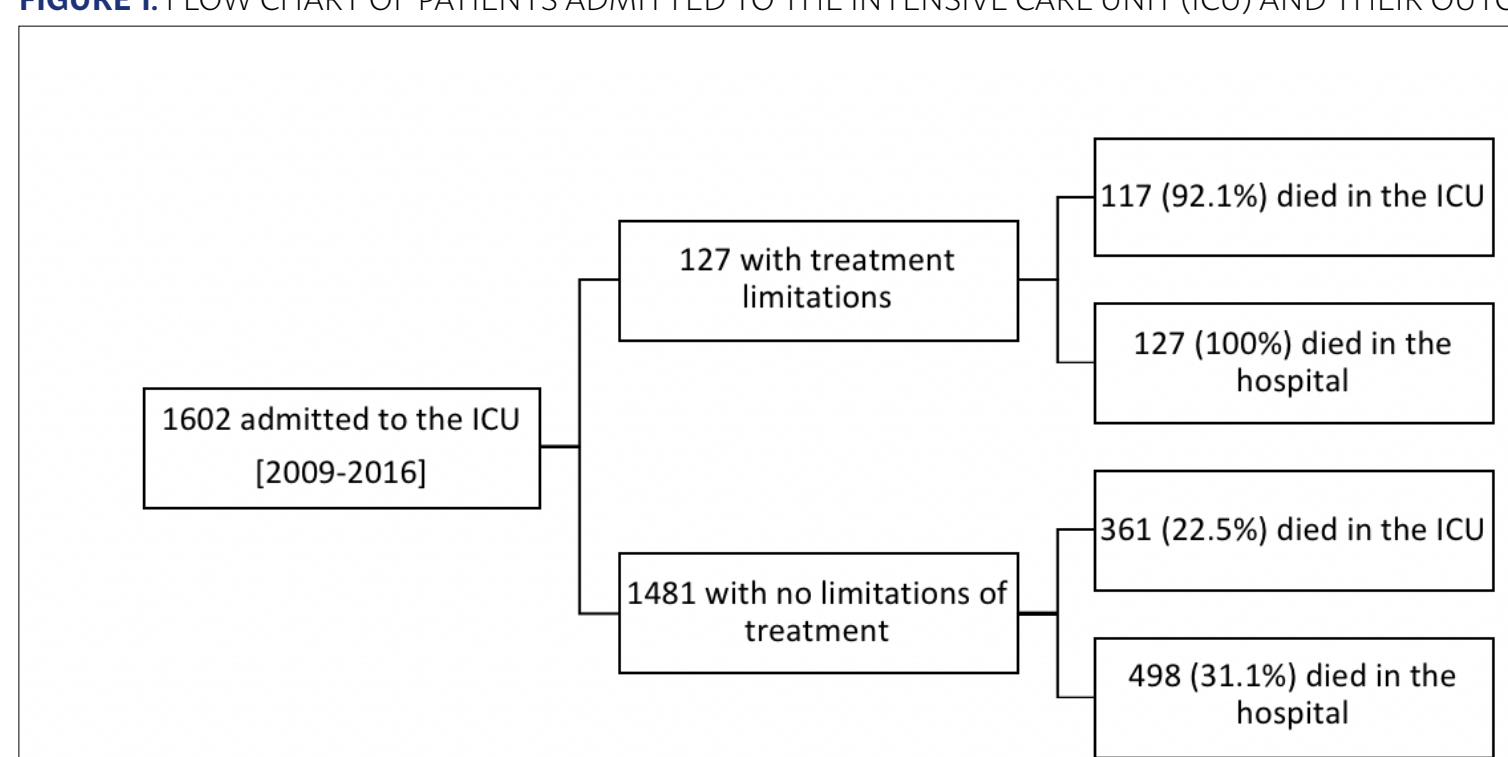


Of the studied population, 90.6\% $(n=115)$ of patients received mechanical ventilation, for a mean duration of 12.0 days $( \pm 12.5)$; $45.7 \%(n=58)$ of these patients received dialysis at some point prior to therapeutic limitation decisions, for a mean duration of 10.0 days $( \pm 9.6)$; and $19.7 \%(n=25)$ received parenteral nutrition for a mean duration of 14.6 days $( \pm 11.7)$. The template form for therapeutic limitation decisions did not specify which treatment options were withdrawn or withheld, nor was this information consistently featured on clinical records. Likewise, we could not determine the number of patients in whom withdrawal of all life-sustaining treatments happened on the same day, or incrementally across several days.

\section{DISCUSSION}

Although this study confirms that limitation of treatment has become a relatively common practice in ICUs, it also serves to underline the geographical differences which have already been noted in several other publications. There is a well-documented geographical pattern to the disparity in ICU end-of-life practices in the Northern Europe when compared with Southern, having a significantly higher rate of withholding and withdrawal of life-sustaining therapies. ${ }^{2}$ Similar disparities in treatment limitation approaches have also been described between continents like North America and Europe when compared to Asia, particularly of Middle Eastern countries ${ }^{10-12}$. Case-mix, religion, culture, jurisdictional law, individual physician, and institutional characteristics are known to be contributing factors ${ }^{2}$.

To demonstrate, whereas in this study treatment limitation decisions were made in just under $8 \%$ of around 1600 admitted patients, similar works from Northern Europe report a considerably higher prevalence of DNR decisions - for example, Hoel et al..$^{13}$ have registered a number of DNR decisions close to $25 \%$ in 1200 patients in their single-center study in a Norwegian ICU. Likewise, a single-center study by Yazigi et al. ${ }^{12}$, conducted in a Lebanese ICU, has reported an incidence of treatment limitation directives in under $10 \%$ of 446 patients.

Factors associated with limitation of treatment were older age, higher estimated mortality, and higher SAPS II score (despite this severity score not having been designed to estimate individual risk). Regarding patients' age, although it was never cited as being a factor in the decision to limit treatment, limitations
TABLE 1. DIAGNOSES AT THE TIME OF WITHDRAWAL OR WITHHOLDING LIFE-SUSTAINING TREATMENT

\begin{tabular}{l|l|l} 
& $\mathbf{n}$ & $\%$ \\
\hline Sepsis & 66 & 52.0 \\
\hline Neurological & 21 & 16.5 \\
\hline Respiratory failure & 13 & 10.2 \\
\hline Malignant disease & 9 & 7.1 \\
\hline Cardiovascular failure & 9 & 7.1 \\
\hline Multiple-organ failure & 4 & 3.1 \\
\hline Renal failure & 3 & 2.4 \\
\hline Gastrointestinal & 1 & 0.8 \\
\hline Hepatic failure & 1 & 0.8 \\
\hline
\end{tabular}

TABLE 2. PREDICTORS OF TREATMENT LIMITATION DECISIONS AS DOCUMENTED IN MEDICAL RECORDS

\begin{tabular}{l|l|l|l|l} 
& $\begin{array}{l}\text { Withholding } \\
\mathrm{N}=52\end{array}$ & $\begin{array}{l}\text { Withdrawal } \\
\mathrm{N}=35\end{array}$ & $\begin{array}{l}\text { Total } \\
\mathrm{N}=87\end{array}$ & $\mathrm{P}$ \\
\hline $\begin{array}{l}\text { Non-response to } \\
\text { treatment }\end{array}$ & $49(56.3)$ & $32(36.8)$ & $81(93.1)$ & $<0.01$ \\
\hline $\begin{array}{l}\text { Limited subsequent } \\
\text { relational QOL }\end{array}$ & $26(29.9)$ & $17(19.5)$ & $43(49.4)$ & $<0.01$ \\
\hline $\begin{array}{l}\text { Limited autonomy } \\
\text { before admission }\end{array}$ & $25(28.7)$ & $14(16.1)$ & $39(44.8)$ & $<0.01$ \\
\hline $\begin{array}{l}\text { Absence of curative } \\
\text { therapy }\end{array}$ & $9(10.3)$ & $8(9.2)$ & $17(19.5)$ & $<0.01$ \\
\hline $\begin{array}{l}\text { End-stage incurable } \\
\text { severe disease }\end{array}$ & $8(9.2)$ & $5(5.7)$ & $13(14.9)$ & $<0.01$ \\
\hline
\end{tabular}

Values are represented as number (\%). QOL = quality of life.

TABLE 3. INCIDENCE OF TREATMENT LIMITATION DECISIONS BASED ON TYPE OF PATIENT ADMISSION

\begin{tabular}{l|l|l|l}
\multicolumn{1}{c}{} & $\begin{array}{l}\text { Scheduled } \\
\text { Surgical } \\
\mathrm{N}=6\end{array}$ & $\begin{array}{l}\text { Unsched- } \\
\text { uled Surgical } \\
\mathrm{N}=22\end{array}$ & $\begin{array}{l}\text { Medical } \\
\mathrm{N}=99\end{array}$ \\
\hline Treatment withheld & $3(50.0)$ & $12(54.5)$ & $72(56.7)$ \\
\hline Treatment withdrawn & $1(16.7)$ & $9(40.9)$ & $31(31.3)$ \\
\hline
\end{tabular}

Values are represented as number (\%).

were more frequent in older patients. This suggests age was indeed part of the clinical assessment that led to these decisions, as has also been proposed by other studies ${ }^{14}$.

A considerably higher number of patients had treatments withheld rather than withdrawn, which falls in line with other works published in Southern Europe, in comparison with Northern European publications which show a more even ratio of treatment withholding versus withdrawing ${ }^{11,15-17}$.

Similarly to other works, no patient survived the hospital stay after having any treatment withdrawn, and close to half of the patients who died had undergone treatment limitation decisions ${ }^{1,1317}$. The median length of ICU stay was higher in this sample than in other single-center studies - while DNR patients 
specifically had a median length of stay comparable to that reported in other Southern European countries (10 to 12 days), the global length of stay was considerably lower in several other centres, ${ }^{1,2,13,17}$. This difference could perhaps be explained by the lack of an Intermediate Care Unit in our Hospital, which could serve as a bridge of increased vigilance between a patient's ICU discharge and return to a conventional infirmary; it could also perhaps be attributed to the time gap between patient admission and the implementation of DNR/WhWd decisions, or the stuttering withdrawal that was documented in over $40 \%$ of cases. ICU lengths of stay - as well as use of invasive procedures - have consistently been demonstrated to decrease when palliative interventions are adopted in a timely manner, which can result in a long-term decrease in hospital costs ${ }^{18}$.

Regarding the documentation of DNR decisions, there is a wide range of approaches described in several different studies, highlighting a lack of standardized procedures for this process. In the case of our ICU, a specific document - the HELICS-ICU form had already been created, prior to the design of this study, which allowed for the registration of DNR, withholding, and withdrawal decisions and their dates, although it was not specifically designed for this purpose. However, this form may be considered lacking in some aspects, such as the motive(s) behind these decisions, the intervening parties and which specific treatment measures have been withdrawn for each patient. Similarly, clinical records were scarce in regard to this type of information, most often simply bringing to attention that the patient had treatment limitations in place. Furthermore, it should be noted that, in almost $10 \%$ of patients with documented treatment limitations (WhWd) in this form, the accompanying DNR decision was not formally registered at the same time; this can perhaps be attributed to oversights when filling out the HELICS-ICU form, which should ideally be minimized. When compared to other published works, it becomes clear that there is room for improvement, but also that this problem persists in several other ICUs: several Asian centers go into detail regarding the intervening elements in the decision process, demonstrating a considerable input from family members or surrogates while very little contribution from nursing staff ${ }^{11,12}$; a French study by Lesieur et al. ${ }^{1}$ developed a specific form to document reasons for
WhWd decisions, participants, and type of treatment withheld. Esteban et al. ${ }^{17}$ also recorded specific data pertaining to the participants in the decision and the type of discussion with family members or surrogates. It should be noted, however, that these two studies were prospective in nature, which made it possible to optimize the data collection process. The retrospective study by Hoel et al. ${ }^{13}$ also brought to attention the lack of detail in clinical records, which made it difficult to ascertain data like patient and relatives' input in the decisions, as well as the accurate timing of the formal written directives in relation to the medical staff's actual moment of treatment limitation decision.

Our study has some limitations. As a retrospective study, it heavily relied on computerized clinical records for data collection, which were naturally liable to variable interpretations. At the same time, this highlights there is room for improvement regarding the level of detail in the process of documentation of treatment limitation decisions. Also, this study was carried out in a single general ICU, which may not allow for the generalization of results to other institutions with different settings and populations.

\section{CONCLUSION}

Steady advances are being made regarding decisions to limit life-sustaining treatments in the ICU. Nowadays, there is a clear notion that timely implementation of a palliative-focused approach, when adequate, improves patient quality of life while simultaneously resulting in lower ICU lengths of stay. However, in comparison to regions such as North America or Northern Europe, there is still room for improvement in our practice on several fronts, among which: more detailed documentation of these decisions, focus on a shared-decision model (medical and nursing staff as well as family members) and commitment to the treatment limitations decided upon, so as to avoid stuttering withdrawal and prolonged continuation of potentially futile measures.

\section{Acknowledgments}

The authors would like to thank secretary Paula Sacramento for her contributions to this work.

The authors have no professional or financial conflicts of interests to declare. 


\section{RESUMO}

OBJETIVO: Decisões de limitação terapêutica (DLT) e de não reanimação (DNR) são difíceis, mas importantes, visando melhorar a qualidade de vida dos doentes e minimizar distanásia. O objetivo deste estudo foi avaliar a abordagem das DNR e DLT, as características dos doentes e a documentação dessas decisões numa Unidade de Cuidados Intensivos Polivalente (Ucip) em Portugal.

MÉTODOS: Análise retrospectiva dos dados referentes a DLT e DNR, recolhidos a partir de formulários previamente elaborados e complementados por consulta de processo clínico.

RESULTADOS: Um total de 1.602 doentes foi internado na Ucip entre 2011 e 2016. DNR foi documentada em 127 casos (7,9\%). Doentes com DLT eram mais velhos e tinham um Simplified Acute Physiology Score II mais elevado. O diagnóstico mais frequente que precedeu essas decisões foi sepse (52,0\%, $n=66)$; A razão mais comum para limitar o tratamento foi mau prognóstico da doença aguda. Dos doentes nos quais a DNR foi implementada, 117 (92,1\%) morreram na Ucip (40,1\% do total de óbitos na Ucip) e a mortalidade hospitalar foi de $100 \%$. Os intervenientes nessas decisões, bem como os tipos de tratamento retirados, não foram rotineiramente registrados.

CONCLUSÃO: As DLT e DNR foram relativamente comuns, em consonância com outros estudos do sul da Europa, mas atrás dos centros do norte da Europa e da América do Norte. Os doentes com essas limitações eram mais velhos e mais gravemente doentes. A documentação dessas decisões deve ser clara e detalhada, seja em formulários específicos, seja em registros clínicos informatizados. Há espaço para melhorias nessa área.

PALAVRAS-CHAVE: Cuidados paliativos. Cuidados críticos. Ordens quanto à conduta (ética médica). Estado terminal. Suspensão de tratamento.

\section{REFERENCES}

1. Lesieur O, Leloup M, Gonzalez F, Mamzer MF; EPILAT study group. Withholding or withdrawal of treatment under French rules : a study performed in 43 intensive care units. Ann Intensive Care. 2015;5(1):56.

2. Connolly C, Miskolci O, Phelan D, Buggy DJ. End-of-life in the ICU: moving from "withdrawal of care" to a palliative care, patient-centred approach. $\mathrm{Br}$ J Anaesth. 2016;117(2):143-5.

3. Coelho CBT, Yankaskas JR. New concepts in palliative care in the intensive care unit. Rev Bras Ter Intensiva. 2017;29(2):222-30.

4. Fuchs L, Anstey M, Feng M, Toledano R, Kogan S, Howell MD, et al. Quantifying the mortality impact of do-not-resuscitate orders in the ICU. Crit Care Med. 2017;45(6):1019-27.

5. Gerstel E, Engelberg RA, Koepsell T, Curtis JR. Duration of withdrawal of life support in the intensive care unit and association with family satisfaction. Am J Respir Crit Care Med. 2008;178(8):798-804.

6. Halcomb E, Daly J, Jackson D, Davidson P. An insight into Australian nurses' experience of withdrawal/withholding of treatment in the ICU. Intensive Crit Care Nurs. 2004;20(4):214-22.

7. Patel SS, Holley JL. Withholding and withdrawing dialysis in the intensive care unit: benefits derived from consulting the Renal Physicians Association/ American Society of Nephrology Clinical Practice Guideline, shared decision-making in the appropriate initiation of and withdrawal from dialysis. Clin J Am Soc Nephrol. 2008;3(2):587-93.

8. Jensen HI, Ammentorp J, Ording H. Guidelines for withholding and withdrawing therapy in the ICU: impact on decision-making process and interdisciplinary collaboration. Hear Lung Vessel. 2013;5(3):158-67.

9. Suetens C, Morales I, Savey A, Palomar M, Hiesmayr M, Lepape A, et al. European surveillance of ICU-acquired infections (HELICS-ICU): methods and main results. J Hosp Infect. 2007;65:171-3.
10. Phua J, Joynt GM, Nishimura M, Deng Y, Myatra SN, Chan YH, et al; ACME Study Investigators and the Asian Critical Care Clinical Trials Group. Withholding and withdrawal of life-sustaining treatments in intensive care units in Asia. JAMA Intern Med. 2015;175(3):363-71.

11. Zhao Q, Zhang X, Fang Y, Gong J, Gu B, Ma G. Current situation and associated factors of withdrawing or withholding life support to patients in an intensive care unit of cancer center in China. PLoS One. 2014;9(5):e98545.

12. Yazigi $A$, Riachi M, Dabbar G. Withholding and withdrawal of life-sustaining treatment in a Lebanese intensive care unit: a prospective observational study. Intensive Care Med. 2005;31(4):562-7.

13. Hoel H, Skjaker SA, Haagensen R, Stavem K. Decisions to withhold or withdraw life-sustaining treatment in a Norwegian intensive care unit. Acta Anaesthesiol Scand. 2014;58(3):329-36.

14. Brandberg $\mathrm{C}$, Blomqvist $H$, jirwe $M$. What is the importance of age on treatment of the elderly in the intensive care unit? Acta Anaesthesiol Scand. 2013;57(6):698-703.

15. Hemphill JC 3rd. Do-not-resuscitate orders, unintended consequences, and the ripple effect. Crit Care. 2007;11(2):121.

16. Vincent JL. Withdrawing may be preferable to withholding. Crit Care. 2005;9(3):226-9.

17. Esteban A, Gordo F, Solsona |F, Alía I, Caballero |, Bouza C, et al. Withdrawing and withholding life support in the intensive care unit: a Spanish prospective multi-centre observational study. Intensive Care Med. 2001;27(11):1744-9.

18. Aslakson R, Cheng J, Vollenweider D, Galusca D, Smith TJ, Pronovost PJ. Evidence-based palliative care in the intensive care unit: a systematic review of interventions. J Palliat Med. 2014;17(2):219-35. 